\title{
Clinical governance: application to psychiatry
}

\author{
Femi Oyebode, Nick Brown and Elizabeth Parry
}

The Government White Paper The New NHS: Modern, Dependable (Department of Health, 1997) introduced the concept of "clinical governance' as a tool for ensuring that high clinical standards are met, and that processes are in place to ensure continuous improvement in clinical practice within trusts. This concept, although currently loosely defined, is to be backed up by a new statutory duty for quality within the National Health Service (NHS). The arrangements are such that chief executives will carry ultimate responsibility for assuring the quality of services provided by trusts and will be accountable officers, much in the same way that they are accountable officers for the proper use of resources. The White Paper suggests that "Chief Executives will be expected to ensure there are appropriate local arrangements to give them and the NHS Trust board firm assurances that their responsibilities for quality are being met" (Department of Health, 1997). It is suggested that this might be through the creation of a Board Sub-Committee, led by a named senior consultant, nurse, or clinical professional, with responsibility for ensuring the internal clinical governance of the organisation, while emphasising the importance of engaging professionals at service delivery level. Since then, a series of consultation documents, including A First Class Service: Quality in the New NHS (Department of Health, 1998a), have been published which develop the concept of clinical governance further.

Clinical governance, as a concept, must be understood in the context of the notion of 'corporate governance'. Corporate governance is a means by which the probity and integrity of financial transactions of institutions, be they private or public, are assured. The assurance mechanisms include explicit duties imposed on officers of institutions, clearly delineated responsibilities with identifiable accountable individuals in the event of failures and strict rules of conduct which ensure transparency in the financial transactions of these institutions. Corporate governance can, thus, be seen both as an assurance and a control mechanism. The explicit duties, responsibilities and accountabil- ity structures serve to assure the public by indicating the designated individuals whose role it is to oversee the financial integrity of institutions. On the other hand, the rules of conduct are the control measures which dictate the procedures and practices necessary to ensure financial probity. Corporate governance served to alert board members to their responsibilities $v i s-\dot{a}-v i s$ the financial management of institutions of which they were guardians. This context emphasises that the introduction of clinical governance is as much about introducing assurance and control mechanisms to guarantee that clinical interventions produce desirable effects and are delivered by competent practitioners as it is about re-instituting clinical issues into the management agenda of the NHS. This is further apparent in the proposals to establish a National Institute for Clinical Excellence (NICE) which will promote clinical effectiveness and a national Commission for Health Improvement (CHI), whose role will be to support and oversee the quality of clinical governance and of clinical services, offering an independent guarantee that local systems to monitor, assure and improve clinical quality are in place.

There is little doubt that, since the publication of The New NHS, Modern and Dependable (Department of Health, 1998b) what is now known as 'The Bristol Case' has sharpened the discussion about clinical governance. In the wake of the General Medical Council's inquiry into the cases of 53 babies treated in the paediatric cardiac surgery unit at Bristol Royal Infirmary, there is a call for a more transparent system of audit of the outcome of clinical interventions. The case can be seen as a study in the failure of quality assurance systems and clearly clinical governance as a concept has an important role to play in such a process. Most commentators remark on the need for such mechanisms in order both to restore public confidence in the NHS and to renegotiate medicine's contract with patients (Keogh et al, 1998; Smith, 1998).

The introduction of clinical governance will bring clinical matters to the attention of NHS 
trust boards. There is little doubt that the previous NHS reforms encouraged an ethos where the business of boards was dominated, almost exclusively, by financial issues. It was rare for clinical considerations to be central to discussions or decisions of boards and indeed only two of the 11 board members were required to have a clinical background. This, in our view, created a gulf between NHS managers and the clinicians responsible for delivering the care to patients. Management decisions were treated with suspicion and scepticism by clinicians. Managers were perceived as having to implement constant and relentless cuts in resources without regard to the implications for clinical practice, whether or not this was actually the case, whereas clinicians saw themselves as struggling against the odds to maintain a semblance of an adequate clinical service. The irony, of course, is that for a decade or so the health service was managed as if clinical matters were peripheral to its main concern and it has had to take a new Government to re-focus the energy of managers to the principal, if not the sole, aim of a health service, which is to provide clinical services, even if this is within financial constraints. Clinical governance stands the chance of facilitating the convergence of managerial and clinical agenda because, for the first time, chief executives are charged with and accountable for, both fiscal rectitude and adherence to high clinical standards.

In this paper we describe our proposal for clinical governance within mental health trusts. We believe that it is important that there is wide discussion about the concept of clinical governance and how it might be translated into reality to begin the process of meaningful engagement with clinical staff. We would also argue that the concept should be allowed to develop over time in the light of experience. We suggest that the structures and arrangements for clinical governance in trusts, the business which is handled by clinical governance committees, the manner of integration of quality and clinical effectiveness data into clinical governance processes should all be relatively uniform across the country. If the concept of clinical governance is taken in conjunction with the expressed aims of the Green Paper Our Healthier Nation (Department of Health, 1998c), which are to improve the health of the population as a whole and to reduce health inequalities, then a national approach to the tasks set out below is obligatory. There is a risk that, if a body such as the Royal College of Psychiatrists does not show the required leadership, either unnecessarily diverse approaches to clinical governance could evolve across the country resulting in fragmented and incoherent systems, or guidance will be issued by, for example, the NHS Executive and an opportunity for mental health staff to influence its development will have been missed. In either event, the potential for improving psychiatric care and services in a meaningful and measurable way will have been reduced.

It could be argued that an unduly centralised approach to clinical governance whereby all NHS trusts, irrespective of their local situation, await guidelines from, for example, NICE would produce an undesirable passivity in clinicians. It is always the case that a balance has to be struck between centrally laid down policy or criteria and the flexibility for local institutions to interpret and implement these policies in the light of their own environment. Our view is that there is an unjustifiable variation in the disposition of mental health services in the country such that a firmer guideline from the centre would not be amiss at this point in time. The reality of course is that NICE and CHI will have a role in leading and guiding the NHS on clinical governance issues.

\section{Remit and membership of clinical governance committees}

The remit of the clinical governance committee is stipulated in a general way in the White Paper (Department of Health, 1997): "There will be a new system of clinical governance in NHS Trusts and primary care to ensure that clinical standards are met, and that processes are in place to ensure continuous improvement". Incorporated into the purpose of clinical governance are a number of distinct but related tasks which include quality improvement programmes, clinical audit processes, introduction of evidencebased practice, dissemination of clinical guidelines and practice standards, clinical risk management programmes, monitoring of adverse events and complaints, systematic professional development programmes, and the monitoring of poor clinical performance. The underlying theme of these differing tasks speaks to the wish to improve the quality of care within the NHS.

Our intention in our argument on the nature of the committees is not to lay down inflexible structures. It is important to emphasise that, in discussion with our local colleagues, it is clear to us that there needs to be some guidance not only on the principles and values of clinical governance (which is already provided in abundance in Government publications and circulars) but also on the actual structures which colleagues up and down the country may wish to consider for introduction into their own trusts.

The White Paper is silent on the composition of the clinical governance committee, except that it suggests that it be led by a named senior clinician. We propose that an ideal number of 
members is between 10 and 12 . An excessively large number of members is likely to reduce the ability of the committee to work effectively and efficiently. We believe that the committee should reflect the broad range of specialities and professions within any given trust. The majority of members should be actively practising clinicians. The clinicians should not be those who already hold managerial positions. It may be an advantage for professional groups to nominate colleagues to serve a term of office on the committee.

The committee should meet at least once monthly. A rolling programme of work consisting of the broad categories of responsibilities should be set out each year. These broad categories are quality data, clinical practice indicators, clinical audit and clinical guidelines. The minutes and reports, including the annual report on action to assure quality, should be formally received by board meetings. The role for the board needs to be considered in the context of appropriate powers for lay people in relation to clinical matters which they do not have the technical expertise to judge. The mechanisms for disseminating the minutes and reports of the committee outside of the board is crucial, if clinicians are to be influenced by it. There is the possibility that the deliberations of this committee could come to seem detached from the day-to-day concerns of clinicians which would be an undesirable outcome. We believe that the professional structures within trusts, such as medical advisory committees, should have clinical governance as a standing agenda item and medical directors should speak to this item on a monthly basis. Similarly, effective links need to be developed with the training function of the trust so that the business of the clinical governance committee is at the head of the training agenda.

\section{Practice indicators, clinical guidelines and training}

The Government has recently published The New NHS Modern and Dependable (Department of Health, 1998b) which will focus attention on six areas of performance through the use of a number of indicators. The purpose of these indicators will be to highlight issues that may require further investigation and to drive improvement in practice. They will be built into the accountability arrangements for the NHS. Two of these areas are likely to focus particularly on the practice of clinicians: the effective delivery of appropriate health care and efficient utilisation of resources. Currently, only a few of the indicators are directly relevant to contemporary mental health services. We believe that professional bodies such as the Royal College of
Psychiatrists should contribute to the development of these indicators, ensuring that appropriate methodologies are used and that the indicators selected are valid measures of clinician effectiveness and efficiency. It is also important to ensure that the chosen indicators will not inadvertently result in changes to practice that are ultimately against patients' best interests. Furthermore, a uniform set of measures having the confidence of practitioners and applied in a standard way is more likely to produce meaningful changes in the care of patients. There is likely to be a need for an expansion in the kind of national audit programmes which the Royal College of Psychiatrists Research Unit has developed. There is great advantage in being able to make comparisons across regions and nationally rather than just within local institutions.

The White Paper describes the establishment of a "National Institute for Clinical Excellence which will promote clinical and cost effectiveness by producing clinical guidelines and audits, for dissemination throughout the NHS" (Department of Health, 1997). Equally, the systematic dissemination of evaluated good practice, ideas and innovations is encouraged within the concept of clinical governance. Matters of contemporary importance, such as the decision in I. v. Bournewood Community and Mental Health NHS Trust and the revision of the Mental Health Act 1983 Code of Practice, will also need to be considered by the committee. The challenge for the committee is to facilitate the incorporation of identified good practice into daily practice throughout the trust and to develop a strategy for dealing with complaints and litigation that may arise from apparent inconsistent application of such practice.

We would consider that the links between the principles above and the training, particularly continued professional development, would appear inextricable. The overall aim would be to ensure "fitness for purpose". Thus, individual personal development programmes and reviews of those personal development programmes for senior clinical staff would be embedded with a two-way guarantee: on the one hand, individuals would have a clear lead in identifying their educational needs which would be appropriately negotiated with the employing organisation; on the other hand, that employing organisation would have a clear responsibility for ensuring that adequate arrangements for that education to occur would be permanently in place.

\section{Conclusion}

The Government in introducing clinical governance into the NHS has symbolically re-stated the 
centrality of clinical issues to the successful management of a health service. The concept of clinical governance is at present fluid and indeterminate but the purpose is clear: to create a tool to improve the quality of clinical care. Our past experience of clinical audit and clinical effectiveness processes suggests that managers and clinicians will need to develop and share an understanding of their distinct contributions to the actual working of clinical governance for there to be any hope of success. However, if the process is well managed, it may focus trusts' strategies on clinical matters, re-engage clinicians in the process of running the NHS and help to steer the interests of clinicians and managers to the common end of improving clinical care.

\section{References}

DEPARTMENT OF HEALTH (1997) The New NHS: Modern. Dependable. London: HMSO.
- (1998a) A First Class Service: Quality in the New NHS. London: HMSO.

- (1998b) The New NHS Modern and Dependable: A National Framework for Assessing Performance. London: HMSO.

- (1998c) Our Healthier Nation. London: HMSO.

KEOGH, B. E., DuSSEK, J., WATSON, D., et al (1998) Public confidence and cardiac surgical outcome. Brttish Medical Journal, 316, 1759-1760.

SMrTH, R. (1998) Renegotiating medicine's contract with patients. British Medical Journal, 316, 1622-1623.

*Femi Oyebode, Medical Director, South Birmingham Mental Health Trust, Vincent Drive, Edgbaston, Birmingham B15 2TZ; Nick Brown, Medical Director, Solihull Healthcare Trust, Solihull; and Elizabeth Parry, Assistant to Medical Director, South Birmingham Mental Health Trust, Birmingham

*Correspondence 